\title{
Comparison study for body image education of domestic and overseas female college students
}

\author{
Tae-Young Kim* \\ College of Education, Hankuk University of Foreign Studies, Seoul, Korea
}

The 2016 health education index showed such tendency as well including their raised obesity index, and reported that they are much interested in body images appearing externally. Accordingly, in this study, we conducted the self-reported questionnaire aimed at a total of 389 subjects composed of domestic $(n=226)$ and overseas $(n=163)$ female college students from Asia, Europe, and Latin America so as to investigate their body images for face, figure and health through questionnaires. In this context, a survey was conducted with the method of this study, consequently indicating that overseas subjects are more greatly positive and active to body images (face, figure, and health) by health level, exercise preferences, extent of body activities and body weight than domestic ones. These results reflect a different viewpoint between those subjects and reveal that overseas subjects are more committed to maintaining their health through body activities compared to domestic ones. Moreover, it is considered that domestic subjects tend to place a higher value on external beauty rather than beauty in terms of physical health, thereby it is most important to change the beauty values. Therefore, in the future, health education should play a critical role in promoting discussions for plans and practical strategies of improving health between students and in participating actively in health behaviours.

Keywords: Female college student, Body image, Face, Figure, Health, Education

\section{INTRODUCTION}

Body image is common interests of the eastern and western society, in particular, young students are much interested in it. In each country, there are a variety of educations to make body image improve, and it is believed that those are greatly affected by the cultural environments.

Previous studies for body images reveal that most of young women including female college students strongly tend to lose weight through diet due to a growing tendency to desire slim bodies, and point out risks that may be caused by an excessive weight loss in a short period such as hypotension, irregular menstruation, anorexia nervosa and osteoporosis (Lake et al., 2000; Lee, 1993). Body mass index (BMI) is a weight-related factor affecting greatly body images. According to studies of each country, the obesity association in Japan defined a BMI of less than 18.5 as a thin person in the 2000s. In the studies performed by western researchers (Malina and Bouchard, 1991; Roche et al., 1996), they defined thin people using body weight percentage or skinfold thickness. In China, policies for solving social problems related to obesity were established and studies for eating habits, health attitude and nutrition knowledge of college students are conducted. In addition, as an actual case for body images, Sakamaki et al. (2005) indicated that normal BMI was $80.5 \%, 16.6 \%$ in thin people after performing a self-reported questionnaire targeting 540 college students aged 19-24 years, thus suggesting the necessity of educations for regular eating habits and body activities.

In addition, a survey aimed at 191 male and female black students showed that the obesity of black female students was more than that of black male students, and proposed the importance of health education as well as detailed studies for them (Gipson et al., 2005). As a result of a survey for body image satisfaction of fe-
${ }^{\star}$ Corresponding author: Tae-Young Kim (ib) https://orcid.org/0000-0001-6519-5249 College of Education, Hankuk University of Foreign Studies, 107 Imun-ro, Dongdaemun-gu, Seoul 02450, Korea

Tel: +82-2-2173-2202, Fax: +82-2-2173-3934, E-mail: ktyoung66@hanmail.net Received: November 3, 2017 / Accepted: December 7, 2017
This is an Open Access article distributed under the terms of the Creative Commons Attribution Non-Commercial License (http://creativecommons.org/licenses/by-nc/4.0/) which permits unrestricted non-commercial use, distribution, and reproduction in any medium, provided the original work is properly cited. 
male students aimed at 96 college students, female students (85.7\%) with low BMI was highly satisfied with their body images, and female students (45.5\%) with overweight BMI expressed low satisfaction regarding their body images. Collectively, these previous studies have mainly focused on body weight and BMI, however, studies emphasizing body activities as an active measure for improving body images have seldom been conducted.

Therefore, in this study, we will propose education methods for improving body images in an active manner by investigating the difference in body images affected by health level, exercise preferences, extent of body activities, and body weight between domestic and overseas college students owing to diversely expressed body images by countries and cultures, and provide the results as basic materials for subsequent studies.

\section{MATERIALS AND METHODS}

\section{Participants}

Participants ( $n=389)$ for this study were female college students from various parts of domestic (Korea $=226)$ and overseas (Asia, Europe, Central \& Southern America $=163$ ) countries. All participants were undergraduate students with a mean age of 21.3 years.

\section{Measures}

A body image questionnaire was devised to estimate body size and satisfaction with body characteristics. The questionnaire included three parts: Part 1 is anthropometric data, based on the subjects' report of age, sex, body weight, and height. BMI was calculated from measured height and weight. Part 2, a body image rating scale, consists of female faces and figures of increasing

Table 1. Body images by nationality

\begin{tabular}{lcccc}
\hline Body image & Number & Mean \pm SD & $F$ & $P$-value \\
\hline Face & & & 3.353 & 0.068 \\
DFCS & 226 & $3.1 \pm 0.65$ & & \\
OFCS & 162 & $3.24 \pm 0.82$ & & \\
Figure & & & $32.784^{* * *}$ & 0.000 \\
DFCS & 226 & $2.43 \pm 0.85$ & & \\
OFCS & 162 & $2.96 \pm 0.97$ & & \\
Health & & & $7.629^{* *}$ & 0.006 \\
DFCS & 226 & $3.25 \pm 0.87$ & & \\
OFCS & 162 & $3.49 \pm 0.79$ & &
\end{tabular}

SD, standard deviation; DFCS, domestic female college student; OFCS, overseas female college student.

${ }^{* *} P<0.01 .{ }^{* *} P<0.001$. size with accompanying numerical ratings. Part 3 consists of questions about the subject's health level, exercise preferences and physical activities.

\section{Data analysis}

The IBM SPSS ver. 18.0 (IBM Co., Armonk, NY, USA) was used for data compilation and statistical analysis. All data are reported as mean and standard deviation. Nationality body images were tested with $t$-tests. For the purpose of analysis, $P$-value of less than 0.05 was considered significant and some items of scale was grouped into a single entity such as poor and fair, into fair, and very good and excellent, into excellent.

\section{RESULTS}

\section{Body images of domestic and overseas countries}

As a result of analysing the body images (face, figure, and health) between domestic and overseas countries, there were no significant differences in face between domestic and overseas female college students, but overseas female college students made a much greater positive evaluation about their figure and health than domestic subjects (Table 1).

\section{Body images by health level}

In the overall body images by health level of domestic and overseas subjects, face, figure, and health were respectively evaluated

Table 2. Body images by health level

\begin{tabular}{|c|c|c|c|c|}
\hline Body image & Number & Mean $\pm S D$ & $F$ & Posthoc \\
\hline Face & & & $7.542^{* * *}$ & \\
\hline $\mathrm{Bad}^{\mathrm{a}}$ & 31 & $3.00 \pm 0.67$ & & $a, b<d$ \\
\hline Normal $^{b}$ & 114 & $2.94 \pm 0.69$ & & \\
\hline$G^{\prime} d^{c}$ & 182 & $3.25 \pm 0.72$ & & $b<c$ \\
\hline Very good ${ }^{d}$ & 62 & $3.40 \pm 0.74$ & & \\
\hline Figure & & & $15.040^{* * *}$ & \\
\hline $\mathrm{Bad}^{\mathrm{a}}$ & 31 & $2.13 \pm 0.91$ & & $a, b<c, d$ \\
\hline Normal $^{b}$ & 114 & $2.32 \pm 0.78$ & & \\
\hline Good $^{c}$ & 182 & $2.82 \pm 0.95$ & & \\
\hline Very good ${ }^{d}$ & 62 & $3.05 \pm 0.91$ & & \\
\hline Health & & & $63.117^{* * *}$ & \\
\hline $\mathrm{Bad}^{\mathrm{a}}$ & 31 & $2.19 \pm 0.85$ & & All \\
\hline Normal $^{b}$ & 114 & $2.94 \pm 0.68$ & & \\
\hline Good $^{c}$ & 182 & $3.62 \pm 0.68$ & & \\
\hline Very good ${ }^{d}$ & 62 & $3.88 \pm 0.69$ & & \\
\hline
\end{tabular}

SD, standard deviation.

${ }^{* * *} P<0.001$. 
as 'bad' (31 students, 8.0\%), 'normal' (114 students, 29.3\%), 'good' (114 students, 46.8\%), and 'very good' (62 students, 15.9\%). Among these results, in the case of the domestic female college students, face, figure and health were respectively evaluated as 'bad' (27 students, 11.9\%), 'normal' (81 students, 35.8\%), 'good' (94 students, $41.6 \%$ ), and 'very good' (24 students, 10.6\%), thus showing a high tendency in the 'normal' and 'bad' item. In the case of overseas female college students, face, figure, and health were respectively evaluated as 'bad' (4 students, 2.5\%), 'normal' (33 students, 20.2\%), 'good' (88 students, $54.0 \%)$, and 'very good' (38 students, $23.3 \%$ ), thus showing a high tendency in the 'good' and 'very good' item in contrast to domestic subjects (Table 2, Fig. 1).

\section{Body images by exercise preferences}

As a result of analysing the overall body images by exercise preferences of domestic and overseas female college students, face, figure and health were respectively shown as 'very dislikeable' (12 students, 5.3\%), 'dislikeable' (47 students, 12.1\%), 'normal' (139 students, 35.7\%), 'likeable' (152 students, 39.1\%), and 'very likeable' (38 students, 9.8\%). Among these results, in the case of domestic subjects, face, figure and health were respectively evaluated as 'very dislikeable' (12 students, 5.3\%), 'dislikeable' (35 students, $15.5 \%)$, 'normal' (75 students, 32.2\%), 'likeable' (90 students, $39.8 \%$ ), and 'very likeable' (14 students, 6.2\%), thus indicating high scores in the 'normal' and 'likeable' item. Overseas subjects presented a high tendency in the 'normal' and 'likeable' item similarly to domestic ones, that is, face, figure, and health were respectively evaluated as 'very dislikeable' (1 student, $0.6 \%$ ), 'dislikeable' (12 students, $7.4 \%$ ), 'normal' (64 students, 39.5\%), 'like- able' (62 students, 38.3\%), and 'very likeable' (24 students, 14.8\%) (Table 3, Fig. 2).

\section{Body images by extent of body activity}

With regard to the overall body images by extent of body activities of domestic and overseas female college students, face, figure, and health were shown as 'insufficient' (226 students, 68.4\%), 'sufficient' (114 students, 29.3\%), and 'excessive' (8 students, 2.3\%).

Table 3. Body images by exercise preferences

\begin{tabular}{lrrrr}
\hline Body image & Number & Mean \pm SD & $F$ & Post hoc \\
\hline Face & & & $5.594^{* * *}$ & \\
Very dislikeable $^{\mathrm{a}}$ & 13 & $2.89 \pm 0.94$ & & $\mathrm{a}<\mathrm{e}$ \\
Dislikeable $^{\mathrm{b}}$ & 47 & $2.91 \pm 0.84$ & & \\
Normal $^{\mathrm{c}}$ & 139 & $3.05 \pm 0.62$ & & $\mathrm{~b}<\mathrm{d}, \mathrm{e}$ \\
Likeable $^{\mathrm{d}}$ & 152 & $3.3 \pm 0.68$ & & \\
Very likeable $^{\mathrm{e}}$ & 38 & $3.43 \pm 0.88$ & & $\mathrm{c}<\mathrm{d}, \mathrm{e}$ \\
Figure $_{\text {Very dislikeable }}^{\mathrm{a}}$ & 13 & $2.56 \pm 1.1$ & & \\
Dislikeable $^{\mathrm{b}}$ & 47 & $2.26 \pm 0.85$ & & $\mathrm{~b}, \mathrm{c}<\mathrm{d}$ \\
Normal $^{\mathrm{c}}$ & 139 & $2.5 \pm 0.84$ & & \\
Likeable $^{\mathrm{d}}$ & 152 & $2.83 \pm 0.93$ & & $\mathrm{~b}, \mathrm{c}<\mathrm{e}$ \\
Very likeable $^{\mathrm{e}}$ & 38 & $3.07 \pm 1.12$ & & \\
Health & & & $8.678^{* * *}$ & \\
Very dislikeable $^{\mathrm{a}}$ & 13 & $2.85 \pm 1.27$ & & $\mathrm{a}, \mathrm{b}, \mathrm{c}<\mathrm{d}$ \\
Dislikeable $^{\mathrm{b}}$ & 47 & $3.08 \pm 0.91$ & & \\
Normal $^{\mathrm{c}}$ & 139 & $3.18 \pm 0.72$ & & \\
Likeable $^{\mathrm{d}}$ & 152 & $3.53 \pm 0.81$ & \\
Very likeable $^{\mathrm{e}}$ & 38 & $3.78 \pm 0.86$ & \\
\hline
\end{tabular}

\section{SD, standard deviation.} ${ }^{* * *} P<0.001$.
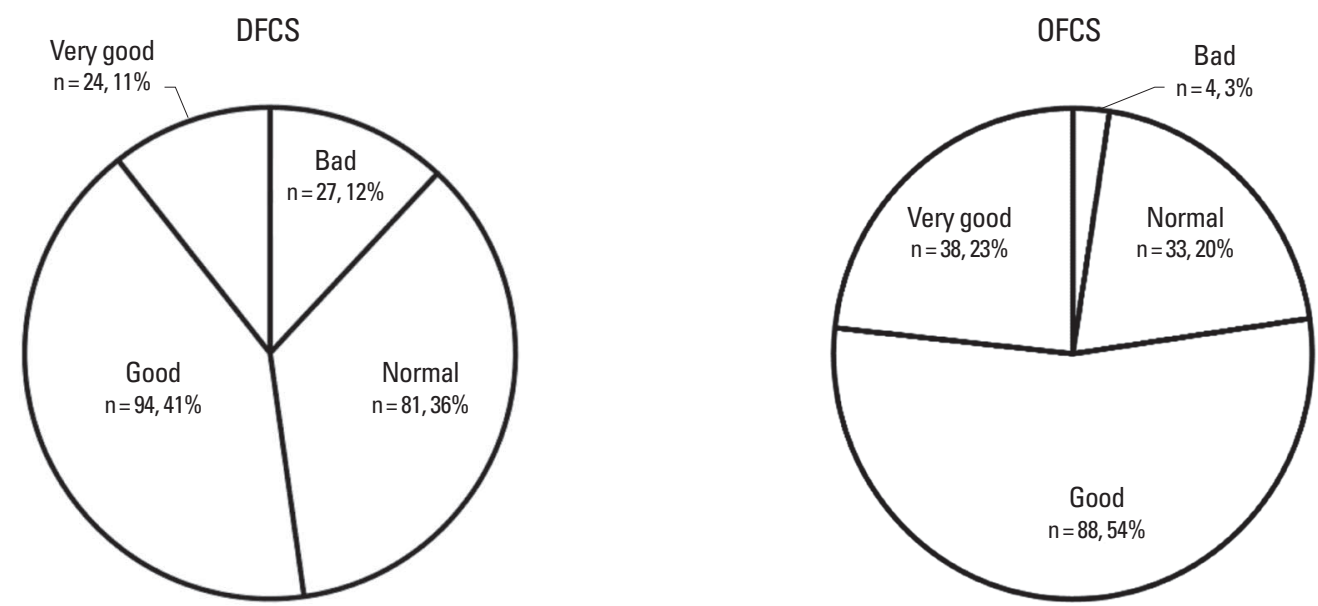

Fig. 1. Body images by health level of domestic and overseas female college students (face, figure, and health). DFCS, domestic female college student; OFCS, overseas female college student. 

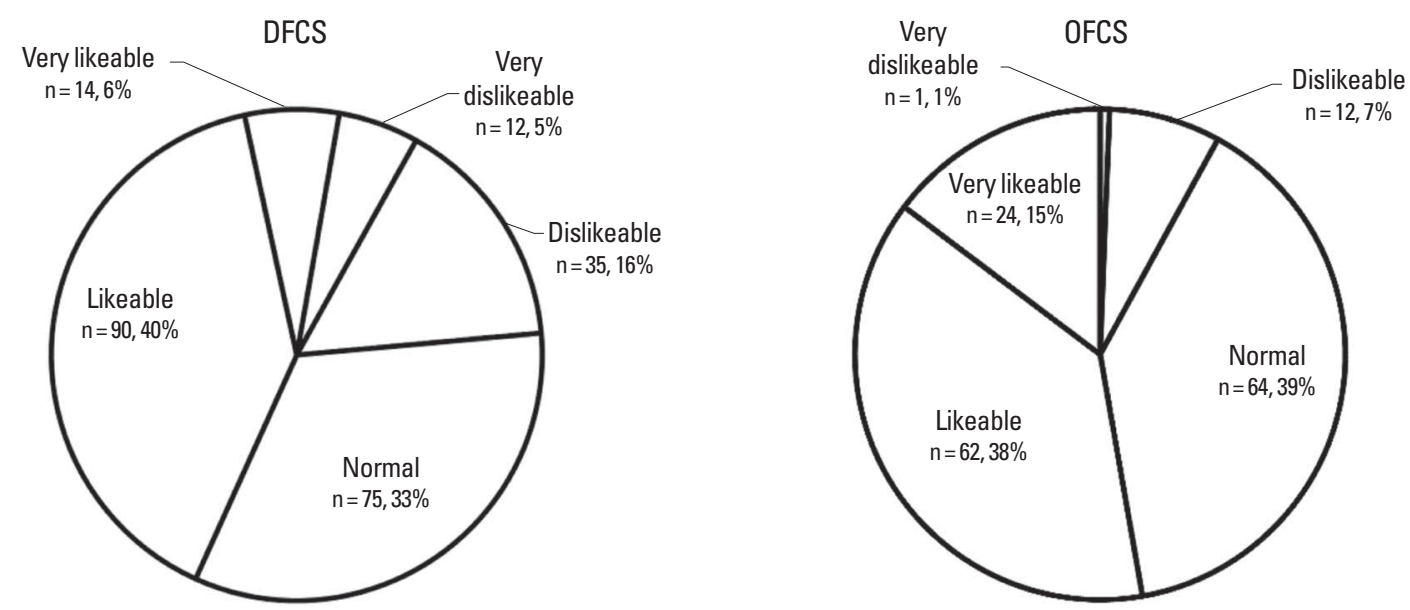

Fig. 2. Body images by exercise preferences of domestic and overseas female college students (face, figure, and health). DFCS, domestic female college student; OFCS, overseas female college student.

Table 4. Body images by extent of physical activities

\begin{tabular}{|c|c|c|c|c|}
\hline Body image & Number & Mean $\pm S D$ & $F$ & Posthoc \\
\hline Face & & & $5.287^{* *}$ & \\
\hline Insufficient ${ }^{\mathrm{a}}$ & 266 & $3.08 \pm 0.74$ & & $a<b$ \\
\hline Sufficient ${ }^{b}$ & 114 & $3.32 \pm 0.69$ & & \\
\hline Excessive $^{c}$ & 9 & $3.47 \pm 0.51$ & & \\
\hline Figure & & & $11.917^{* * *}$ & \\
\hline Insufficient ${ }^{\mathrm{a}}$ & 266 & $2.52 \pm 0.91$ & & All \\
\hline Sufficient ${ }^{b}$ & 114 & $2.91 \pm 0.93$ & & \\
\hline Excessive $^{c}$ & 9 & $3.56 \pm 0.75$ & & \\
\hline Health & & & $6.945^{* *}$ & \\
\hline Insufficient ${ }^{\mathrm{a}}$ & 266 & $3.24 \pm 0.86$ & & $a<b$ \\
\hline Sufficient ${ }^{b}$ & 114 & $3.57 \pm 0.77$ & & \\
\hline Excessive $^{\mathrm{c}}$ & 9 & $3.69 \pm 0.75$ & & \\
\hline
\end{tabular}

$\mathrm{SD}$, standard deviation.

${ }^{* *} P<0.01$. ${ }^{* *} P<0.001$.

Among these results, domestic female college students showed high proportion in the 'insufficient' item. In detail, face, figure, and health were evaluated as 'insufficient' (171 students, 75.7\%), 'sufficient' (51 students, 22.6\%), and 'excessive' (4 students, 1.7\%). In the case of the overseas females, face, figure, and health were evaluated as 'insufficient' (95 students, 58.3\%), 'sufficient' (63 students, 38.7\%), and 'excessive' ( 5 students, 3.0\%), thus indicating a higher tendency in the 'insufficient' and 'excessive' item (Table 4, Fig. 3).

\section{Body images by weight}

In the overall body images by weight of domestic and overseas female college students, face, figure, and health were respectively
Table 5. Body images by weight

\begin{tabular}{|c|c|c|c|c|}
\hline Body image & Number & Mean \pm SD & $F$ & Posthoc \\
\hline Face & & & $3.643^{* *}$ & \\
\hline Underweight ${ }^{\mathrm{a}}$ & 10 & $2.64 \pm 0.72$ & & $a<b, c$ \\
\hline Little underweight ${ }^{b}$ & 35 & $3.41 \pm 0.75$ & & \\
\hline Standard weight ${ }^{c}$ & 196 & $3.22 \pm 0.71$ & & $b>d, e$ \\
\hline Little overweight ${ }^{d}$ & 112 & $3.05 \pm 0.69$ & & \\
\hline Overweight & 36 & $3.04 \pm 0.84$ & & $c>d$ \\
\hline Figure & & & $27.732^{* * *}$ & \\
\hline Underweight & 10 & $2.67 \pm 0.82$ & & $a<b, a>e$ \\
\hline Little underweight $^{b}$ & 35 & $3.28 \pm 0.79$ & & \\
\hline Standard weight ${ }^{c}$ & 196 & $2.95 \pm 0.86$ & & $b>c, d, e$ \\
\hline Little overweight $^{d}$ & 112 & $2.22 \pm 0.81$ & & \\
\hline Overweight ${ }^{\mathrm{e}}$ & 36 & $1.81 \pm 0.77$ & & $c>d, e$ \\
\hline Health & & & $3.149 *$ & \\
\hline Underweighta & 10 & $2.58 \pm 0.77$ & & $a<b, c, d, e$ \\
\hline Little underweight ${ }^{b}$ & 35 & $3.44 \pm 0.81$ & & \\
\hline Standard weight ${ }^{c}$ & 196 & $3.43 \pm 0.8$ & & \\
\hline Little overweight $^{d}$ & 112 & $3.26 \pm 0.88$ & & \\
\hline Overweight & 36 & $3.30 \pm 0.90$ & & \\
\hline
\end{tabular}

${ }^{*} P<0.05 .{ }^{* *} P<0.01 .{ }^{* * *} P<0.001$.

evaluated as a 'underweight' (10 students, 2.6\%), 'little underweight' (35 students, 9.0\%), 'standard weight' (196 students, 50.4\%), 'little overweight' (112 students, 28.8\%), and 'overweight' (36 students, 9.2\%). In the case of domestic female college students, face, figure, and health were respectively evaluated as 'underweight' (7 students, 3.1\%), 'little underweight' (25 students, 11.1\%), 'standard weight' (105 students, $46.5 \%$ ), 'little overweight' (66 students, 29.2\%)' and 'overweight' (23 students, $10.1 \%)$, thus showing higher scores in the 'standard weight' and 

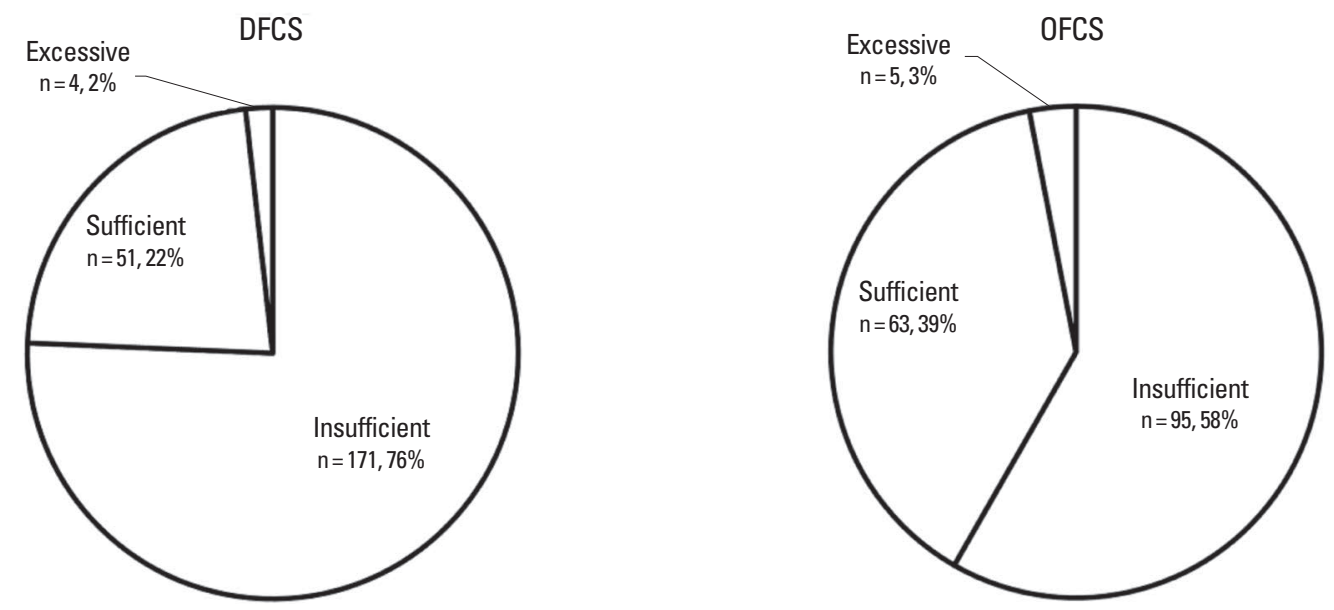

Fig. 3. Body images by extent of physical activities of domestic and overseas female college students (face, figure, and health). DFCS, domestic female college students; OFCS, overseas female college student.
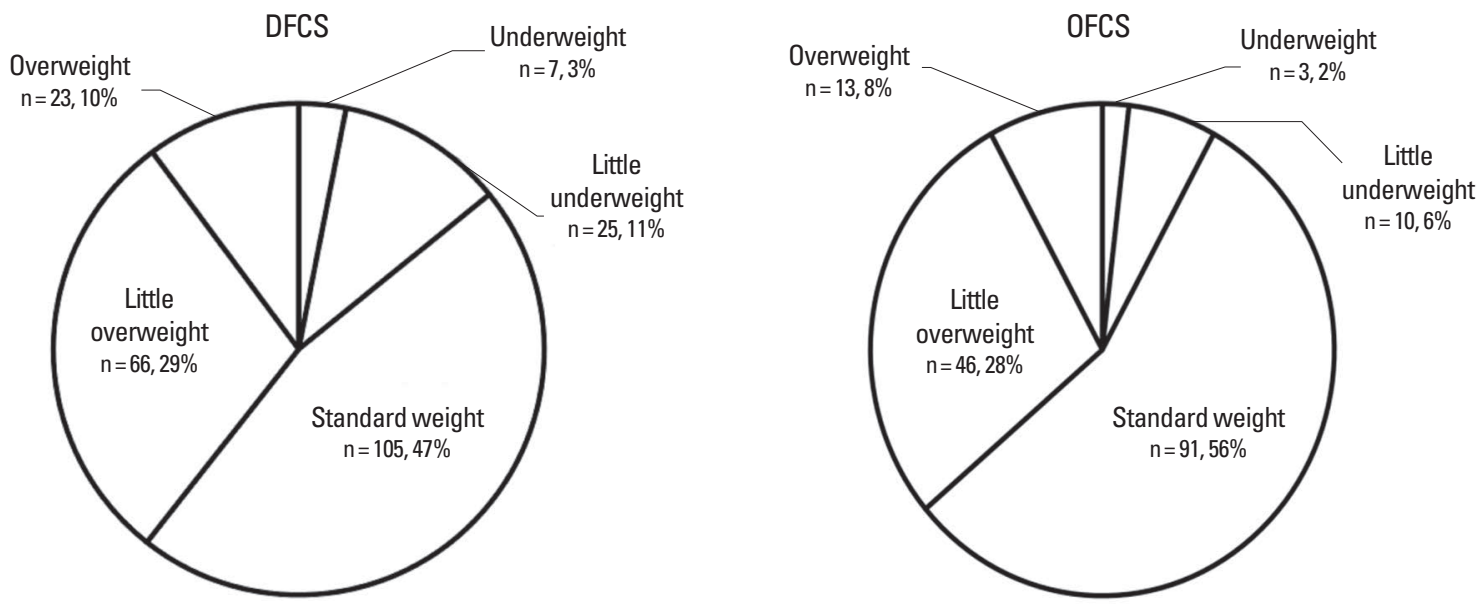

Fig. 4. Body images by weight of domestic and overseas female college students (face, figure, and health). DFCS, domestic female college student; OFCS, overseas female college student.

'little overweight' item. Overseas subjects presented also higher percentage in the 'standard weight' and 'little overweight' item similarly to domestic ones, that is, face, figure and health were respectively shown as a 'underweight' (3 students, $1.8 \%$ ), 'little underweight' (10 students, 6.1\%), 'standard weight' (91 students, $55.8 \%$ ), 'little overweight' (46 students, 28.2\%), and 'overweight' (13 students, 7.9\%) (Table 5, Fig. 4).

\section{DISCUSSION}

This study aims to compare a set of values for body images between domestic and overseas female college students and utilize the relevant results as basic materials for education. For these purposes, we performed a self-reported questionnaire-based survey on body images targeting domestic and overseas female college students within the range of BMI $\left(18.5-26.0 \mathrm{~kg} / \mathrm{m}^{2}\right)$, whose average height and body weight are $162.0 \mathrm{~cm}$ and $54.6 \mathrm{~kg}$ respectively. And any health issues including mental disorders were not found in those female students.

As a result of analysing the difference in body images dividing them into face, figure, and health between domestic and overseas subjects, there were significant differences in figure and health except for face, thus showing that overseas subjects made a greater positive evaluation about figure and health compared to the do- 
mestic females. A previous study revealed that people with high satisfaction for body images were mentally as well as physically healthy, and that Asian women were less unsatisfied with weight loss and body images than western women (Goswami et al., 2012). Such a result does not coincide with that of this study. That's because overseas female college students of the study were mostly composed of Asians. Accordingly, it is considered that overseas female college students are more greatly positive to body images and more self-assured than domestic ones.

Concerning the body images by health level, those were evaluated as 'good' and 'very good' by domestic (52.2\%) and overseas (77.3\%) female college students, thus showing a significant difference between the two groups. These results indicate that students who consider their own health level for face, figure and health to be high have a higher level of body images. In addition, as a result of analysing the body images by exercise preferences, extent of body activities and body weight, overseas female college students expressed also more active and positive body image values than domestic subjects. Kim et al. (2002) asserted that healthy students were satisfied with body images and weight compared to unhealthy ones in their study, in contrast, Wharton et al. (2008) pointed out that body images and weight may be negatively associated with weight control of college students, and that needless weight control may lead eating habits in a wrong direction (Ryu and Yoon, 2000). Therefore, body images can be affected by diverse factors such as sex, age, height, BMI, rice style, eating habit, and cultural and environmental difference. In this study, overseas female college students were shown to be more greatly active and positive to body images, and such a result suggest that national and cultural differences may have an effect on body images. In this regard, Musaiger and Al-Mannai (2013) showed that, as a result of investigating obesity and influence of mass media aimed at 288 female college students of Kuwait, mass media played an important role in reducing body weight, and that $30 \%$ of female college students with normal weight and $81 \%$ of those with obesity were not satisfied with their body weight. These results indicate that colleagues, parents and mass media played a crucial role in losing weight by leading their eating habits in a positive direction. In addition, $19 \%$ of Kuwait female college students and $43 \%$ of Qatar female college students believe strongly that men like overweighted women (Musaiger et al., 2004), and these people still exist in some of Arab countries despite being on the decrease gradually (Musaiger, 2011). Therefore, it should be fully understood that their values for body images may be differently expressed. Moreover, as American black women are generous to overweight and obesity, body images are not affected by those factors. In this context, body images are expressed in various ways according to racial and cultural differences. And a diversity of dissatisfaction rates of body images by each country can be listed in ascending order as follows: China (33\%), Australia (34.9\%), Greece (45\%), Brazil (47.3\%), Taiwan (50\%), Norway (56\%), Turkey (56.7\%), EU (69\%), and America (73.3\%) (Akdevelioglu and Gumus, 2010; Hassapidou, 2006; Hassapidou and Papadopoulou, 2006; Kelly et al., 2005; Luo et al., 2005; McElhone et al., 1999; Meland et al., 2007; O’Dea, 2010; Ozmen et al., 2007; Wong and Huang, 1999). Thus, the dissatisfaction of body images emerges also diversely depending on countries.

This study explored the body image of the overseas subjects and compared them with domestic ones after simply combining female college students from Asia, Europe, and Latin America into overseas ones owing to the lack of alien cases. Accordingly, it is important to investigate male college students as well as female ones by each country in subsequent studies. In conclusion, body image education for domestic female college students should play critical roles in helping them to actively take part in body activities and realize that to keep their face and figure in good condition is to elevate their body images. To this end, detailed educational and practical methods should be explored and prepared. Furthermore, these educations should be led in a positive way through diverse studies for eating habits and life styles.

\section{CONFLICT OF INTEREST}

No potential conflict of interest relevant to this article was reported.

\section{ACKNOWLEDGMENTS}

This work was supported by Hankuk University of Foreign Studies Research Fund of 2017.

\section{REFERENCES}

Akdevelioglu Y, Gumus H. Eating disorders and body image perception among university students. Pakistan J Nutr 2010;9:1187-1191.

Gipson GW, Reese S, Vieweg WV, Anum EA, Pandurangi AK, Olbrisch ME, Sood B, Silverman JJ. Body image and attitude toward obesity in an historically black university. J Natl Med Assoc 2005;97:225-236.

Goswami S, Sachdeva S, Sachdeva R. Body image satisfaction among female college students. Ind Psychiatry J 2012;21:168-172. 
Hassapidou M, Papadopoulou SK. Food choice criteria in adolescents according to body image. Songklanakarin J Sci Technol 2006;28(Suppl 1):165-169.

Kelly AM, Wall M, Eisenberg ME, Story M, Neumark-Sztainer D. Adolescent girls with high body satisfaction: who are they and what can they teach us? J Adolesc Health 2005;37:391-396.

Kim IS, Yu HH, Han HS. Effects of nutrition knowledge, dietary attitude, dietary habits and life style on the health of college students in the Chungnam area. Korean J Community Nutr 2002;7:45-57.

Lake AJ, Staiger PK, Glowinski H. Effect of western culture on women's attitudes to eating and perceptions of body shape. Int J Eat Disord 2000;27:83-89.

Lee $\mathrm{S}$. How abnormal is the desire for slimness? A survey of eating attitudes and behaviour among Chinese undergraduates in Hong Kong. Psychol Med 1993;23:437-451.

Luo Y, Parish WL, Laumann EO. A population-based study of body image concerns among urban Chinese adults. Body Image 2005;2:333345 .

Malina RM, Bouchard C. Growth, maturation, and physical activity. Champaign (IL): Human Kinetics; 1991.

McElhone S, Kearney JM, Giachetti I, Zunft HJ, Martínez JA. Body image perception in relation to recent weight changes and strategies for weight loss in a nationally representative sample in the European Union. Public Health Nutr 1999;2(1A):143-151.

Meland E, Haugland S, Breidablik HJ. Body image and perceived health in adolescence. Health Educ Res 2007;22:342-350.

Musaiger AO. Overweight and obesity in eastern mediterranean region: prevalence and possible causes. J Obes 2011;2011:407237.

Musaiger AO, Al-Mannai M. Role of obesity and media in body weight concern among female university students in Kuwait. Eat Behav 2013; 14:229-232

Musaiger AO, Shahbeek NE, Al-Mannai M. The role of social factors and weight status in ideal body-shape preferences as perceived by Arab women. J Biosoc Sci 2004;36:699-707.

O'Dea JA. Studies of obesity, body image, and related health issues among Australian adolescents: how can programs in school interact with and complement each other? J Stud Wellbeing 2010;4:3-16.

Ozmen D, Ozmen E, Ergin D, Cetinkaya AC, Sen N, Dundar PE, Taskin EO. The association of self-esteem, depression and body satisfaction with obesity among Turkish adolescents. BMC Public Health 2007;7:80.

Roche AE, Heymsfield SB, Lohman TG. Human body composition. Champaign (IL): Human Kinetics; 1996.

Ryu HK, Yoon JS. A comparative study of nutrient intakes and health status with body size and weight control experience in adolescent females. Korean J Community Nutr 2000;5:444-451.

Sakamaki R, Toyama K, Amamoto R, Liu CJ, Shinfuku N. Nutritional knowledge, food habits and health attitude of Chinese university students: a cross sectional study. Nutr J 2005;4:4.

Wharton CM, Adams T, Hampl JS. Weight loss practices and body weight perceptions among US college students. J Am Coll Health 2008;56:579584.

Wong Y, Huang YC. Obesity concerns, weight satisfaction and characteristics of female dieters: a study on female Taiwanese college students. J Am Coll Nutr 1999;18:194-200. 